\title{
SISTEMA ÚNICO DE SAÚDE E DEMANDA AMBULATORIAL - OS PACIENTES DO HOSPITAL DAS CLÍNICAS DA FACULDADE DE MEDICINA DE RIBEIRÃO PRETO - USP
}

\author{
UNIFIED HEALTH SYSTEM AND OUTPATIENT CLINIC DEMAND - THE PATIENTS OF THE \\ UNIVERSITY HOSPITAL OF THE FACULTY OF MEDICINE OF RIBEIRÃO PRETO - USP
}

\author{
Manoel Romeu Gutierrez ${ }^{1} \&$ Marco Antonio Barbieri²
}

\begin{abstract}
(1) Médico Assistente; (2) Docente - Departamento de Puericultura e Pediatria da Faculdade de Medicina de Ribeirão Preto da Universidade de São Paulo.

CorRESPONDÊNCIA: Dr. Manoel Romeu Gutierrez - Departamento de Puericultura e Pediatria da Faculdade de Medicina de Ribeirão Preto da Universidade de São Paulo - Av. dos Bandeirantes, 3900 - Ribeirão Preto - SP.
\end{abstract}

GUTIERREZ MR \& BARBIERI MA. Sistema Único de Saúde e demanda ambulatorial - os pacientes do Hospital das Clínicas da Faculdade de Medicina de Ribeirão Preto - USP. Medicina, Ribeirão Preto, 31: 81-98, jan./mar. 1998.

RESUMO: Objetivo - Estudar aspectos sociais, econômicos e a morbidade dos pacientes que demandam os ambulatórios do HCFMRP - USP. Material e Métodos - Foram entrevistados trezentos e oito pacientes, selecionados por processo amostral probabilístico. A morbidade foi descrita pelos respectivos grupos de diagnósticos principais (CID-1975). Resultados - A maioria dos pacientes pertenciam às categorias ocupacionais de baixa renda; $70 \%$ eram economicamente ativos; $40.7 \%$ procediam de Ribeirão Preto (37.1\%, sem encaminhamento); $27.2 \%$, da região do ERSA 50 (18.1\%, sem encaminhamento); $21.6 \%$ dos demais ERSA (24.2\% sem encaminhamento); $10.5 \%$, de outros estados (15.6\%, sem encaminhamento). As triagens representaram $6 \%$ das consultas diárias (77.7\% foram dispensadas); as consultas agendadas dos ambulatórios especializados representaram $75.3 \%$; $18.8 \%$ dos atendimentos foram devidos aos demais procedimentos. Houve maior prevalência de Doenças do Aparelho Respiratório entre os pacientes não encaminhados, e sem diagnóstico ou para investigação (CID 799.9) entre os encaminhados; as maiores demandas foram devidas às Doenças do Sistema Nervoso, Neoplasmas, Diagnósticos Suplementares (V01 a V08) e Doenças do Aparelho Geniturinário. Conclusões - O atendimento ambulatorial mediante a apresentação de guia de referência, na prática, não atende aos pressupostos da hierarquização; um considerável número de pacientes poderia ter sido atendido nas respectivas unidades básicas, sugerindo a sua excludência dos níveis primário e secundário, cujas causas não foram determinadas; a maior demanda relativa foi a dos procedentes de Ribeirão Preto; quanto aos procedimentos, a maior demanda foi devida aos de alto custo e/ou tratamentos prolongados.

UNITERMOS: Sistema de Saúde. Ambulatório Hospitalar. Morbidade. Hospitais Universitários.

\section{INTRODUÇÃO}

A crescente demanda por serviços médicos, ambulatoriais, do Hospital das Clínicas da Faculdade de Medicina de Ribeirão Preto (Campus) - HCFMRPUSP pelos pacientes procedentes de Ribeirão Preto, de outras regiões do Estado de São Paulo, e de outros Estados, tem superado sua capacidade efetiva de oferta de serviços, enquanto hospital de referência para os níveis primário e secundário do Sistema Único de Saúde 
(SUS) - fato verificável pelos longos períodos para agendamentos de consultas médicas em clínicas especializadas, cirurgias eletivas e outros procedimentos. A constituição dessa demanda não pode ser explicada, se vista pela lógica da organização funcional e operacional do SUS - de hierarquização, regionalização e integração - como base técnica e administrativa de todo sistema, concebida e dimensionada para responder pela universalização do atendimento médico em todos os níveis ${ }^{(1)}$.

As hipóteses explicativas globais, até então propostas, têm se fundamentado no marcado empobrecimento de determinadas classes sociais, e, como conseqüência, sua inacessibilidade à assistência médica privada; nas mudanças históricas das políticas de saúde, das últimas décadas, com a incorporação não planejada de grandes contingentes de trabalhadores e seus dependentes à Previdência Social e Assistência Médica (INAMPS); nas práticas médicas mecanicistas, decorrentes dessas mudanças, observadas tanto no âmbito da assistência médica privada quanto no da pública institucional, que tiveram início a partir da oferta de serviços médicos com gratuidade total, ou parcial, por convênios; na expansão e disponibilidade das especialidades médicas e sua crescente dependência das inovações tecnológicas e dos exames subsidiários; na elevação contínua do custo dessa assistência dependente; na subordinação da educação médica e formação profissional a essas práticas, cujo desdobramento tem sido difundir, na população, práticas e saberes, nos quais a assistência médica é apreendida como substitutivo da precariedade das condições de vida e não como exigência das manifestações concretas das doenças ${ }^{(2 / 7)}$. A hipótese alternativa parte do pressuposto que, desde meados da década de 70, quando o setor público passou a responder pela assistência médica individual através do extinto INAMPS, é constatada uma distribuição desigual dos equipamentos de saúde no país. Entre os desdobramentos desta política setorial, assinala-se a concentração, no setor público, inclusive nos serviços médicos contratados pelo Estado, de equipamentos de complexa tecnologia e de alto custo operacional, para procedimentos diagnósticos e terapêuticos cujo acesso e benefício coletivo é questionável ${ }^{(8)}$. A medicalização ou a instrumentalização das doenças passou a ser pressuposto de "saúde" e "bem-estar", gerando na população uma falsa representação do processo saúde-doença ${ }^{(9)}$. Essa concepção de saúde, subordinada à lógica da oferta de recursos médicos, em última instância, está mais de acordo com os interesses econômicos dos presta- dores de serviços do que com os determinados pelas necessidades reais da população, tendendo, assim, a constituir um particular perfil de demanda por serviços especializados, e a reproduzi-lo, com maior intensidade, nos locais com maior concentração desses recursos ${ }^{(10,11)}$ e a excluir dos níveis primário e secundário aqueles pacientes que, presumivelmente, não contribuiriam para a lucratividade do prestador de serviços. COHN et al. 1991, ${ }^{(12)}$ explicitam que

"é a partir daí que tem origem uma característica crucial da saúde: a concepção da assistência médica, muito mais restrita que saúde, como pertinente à esfera pública, e não à privada. Não se constituindo, portanto, saúde como um direito do cidadão e muito menos um dever do Estado, mas, sim, a assistência médica como um serviço, ao qual se tem acesso a partir da clivagem inicial da inserção no mercado de trabalho". ${ }^{(12)}$

Nesse contexto político, o Hospital das Clínicas, concebido como unidade prestadora de serviços com alta concentração de recursos tecnológicos e humanos, cujo objetivo é o trabalho dirigido aos indivíduos para quem a necessidade real de assistência não encontra resposta nos limites técnicos dos níveis primário e secundário, ou seja, como referência hierárquica e apoio para os demais níveis, está sendo, na prática, utilizado como uma extensão desses níveis e não como sua referência hierárquica.

Com o intuito de explicar o fluxo dessa demanda no nível local, sem lhe negar as causas, formulamos duas hipóteses "a priori" - $\mathbf{1}$ - poderia estar sendo constituída pela exclusão da clientela dos demais níveis (primário e secundário), tanto dos serviços de saúde institucionalizados, conveniados ou contratados, não só pela inacessibilidade econômica mas também pela concepção social e valorativa a eles vinculada, e pelas limitações das práticas médicas que encerram ${ }^{(13)} \mathrm{e}$ 2 - pela necessidade real de serviços especializados, os quais, por exigirem procedimentos de complexa tecnologia, via de regra de altos custos e/ou tratamentos de longa duração, não gerando lucro para o prestador de serviços do setor privado, segundo a lógica perversa do empresariamento médico, ficam às expensas do Estado, ampliando, conseqüentemente, a demanda no nível terciário ${ }^{(14)}$. A primeira pode ser respondida pela quantificação das consultas e procedimentos ambulatoriais de pequena e média complexidade - de competência dos níveis primário e secundário - e pelos atendimentos prestados aos pacientes que tiveram acesso ao HC por via extra-sistema, uma vez que esses, uma vez excluídos daqueles níveis, constituem, 
no HC - Campus, uma demanda artificial. A segunda, pelo estudo do perfil da morbidade dos pacientes atendidos nos ambulatórios de especialidades, considerando que as solicitações por procedimentos de maior complexidade, via extra-SUS, ou não formais, têm aumentado consideravelmente.

Este trabalho teve como objetivo estudar a origem da demanda no nível terciário (pela procedência e local dos encaminhamentos) e determinar se a exclusão desses pacientes dos demais níveis, se estiver ocorrendo, a justifica; e analisar o perfil de morbidade dessa clientela, como condição para avaliar os limites dos recursos oferecidos nos demais níveis e como subsídio para a otimização dos recursos humanos e tecnológicos do sistema.

\section{Sistema de Saúde}

Em 1993, o SUS, no Estado de São Paulo, subdividia-se em cinco "Macro Regiões de Saúde”. Aglutinavam como unidades funcionais e administrativas os sessenta e cinco Escritórios Regionais de Saúde (ERSA) - quinze localizados na Região Metropolitana da Grande São Paulo e cinqüenta nas demais Regiões de Governo. O Município de Ribeirão Preto, situado na região Nordeste do Estado, era sede do ERSA-50 (extinto em 1995) ${ }^{(15)}$ - congregava vinte e dois Municípios da Região Administrativa. Interligava-se com as demais regiões e aos outros estados através de uma complexa malha rodoferroviária, configurando a região funcional ou de influência de Ribeirão Preto $^{(16)}$. A região do ERSA-50 era composta pelos seguintes municípios (inclusive seus respectivos distritos e Subdistritos): Altinópolis, Barrinha, Batatais, Brodósqui, Cajuru, Cássia dos Coqueiros, Cravinhos, Dumont, Guariba, Jaboticabal, Jardinópolis, Luiz Antônio, Monte Alto, Pitangueiras, Pontal, Pradópolis, Ribeirão Preto, Santa Rosa de Viterbo, Santo Antônio da Alegria, São Simão, Serra Azul, Serrana e Sertãozinho.

Desde a sua implantação, o SUS contempla a Hierarquização - definida pelo nível crescente de complexidade dos atos e intervenções médicas; a Regionalização - representada pela delimitação de uma base geográfica para todos os níveis de serviços, concentrando, em determinados Municípios, maiores recursos tecnológicos e humanos, e a Integração dos recursos de saúde, ou seja, a utilização conjunta dos recursos existentes, sejam eles Municipais, Estaduais, ou Federais.
Para a assegurar a completa acessibilidade dos pacientes e organização do fluxo dos atendimentos, o SUS foi hierarquizado em três níveis assistenciais (Figura 1).

1 - Nível Primário - Destinado às consultas médicas de clínicas básicas ou para procedimentos simplificados e de baixa complexidade, praticados em ambulatórios. Pertencem a este nível as Unidades Básicas de Saúde (UBS) ou Centros de Saúde (CS) que constituem a via de acesso inicial e formal aos demais níveis. Em decorrência da municipalização dos serviços médicos, este nível passou a ser coordenado, técnica e administrativamente, política e economicamente em regime de cogestão, pelas Secretarias Municipais de Saúde ${ }^{(17)}$.

2 - Nível Secundário - É constituído pela rede de hospitais próprios, conveniados, e ambulatórios de especialidades, e destinado a atendimentos médicos e intervenções cirúrgicas de média complexidade - pelo que é diferenciado por especialidades básicas. Pertencem a este nível os Ambulatórios Regionais de Especialidades (ARE), Ambulatórios Regionais de Saúde Mental (ARSM), Pronto Atendimento Médico (PAM), Unidades Básicas Distritais de Saúde (UBDS) e os hospitais conveniados (filantrópicos ou não).

3 - Nível Terciário - Constituído por hospitais-escola (via de regra, ligados a universidades). É destinado a procedimentos clínicos e/ou cirúrgicos, de média e grande complexidade, em todas as especialidades médicas e referência (apoio) aos demais níveis.

\section{A origem da demanda no sistema de saúde e no HC}

A demanda no SUS tem origem nas respectivas cidades dos pacientes, através das Unidades Básicas de Saúde (UBS) ou Centros de Saúde (CS) - de livre acesso para qualquer pessoa e para os pacientes encaminhados por médicos assistentes do setor privado (mesmo não integrados ao sistema - particulares, conveniados, ou outros). Na eventualidade de esses pacientes necessitarem da intervenção de especialistas, ou de outros procedimentos de média complexidade, são encaminhados para os hospitais ou ambulatórios locais do nível secundário. Aqueles que necessitarem de intervenções de maior complexidade, ou exames específicos, não disponíveis no local, são encaminhados aos hospitais do nível terciário (o que também pode ocorrer em circunstâncias de acidentes ou intercorrências em doentes internados em hospitais conveniados). Esses encaminhamentos entre 


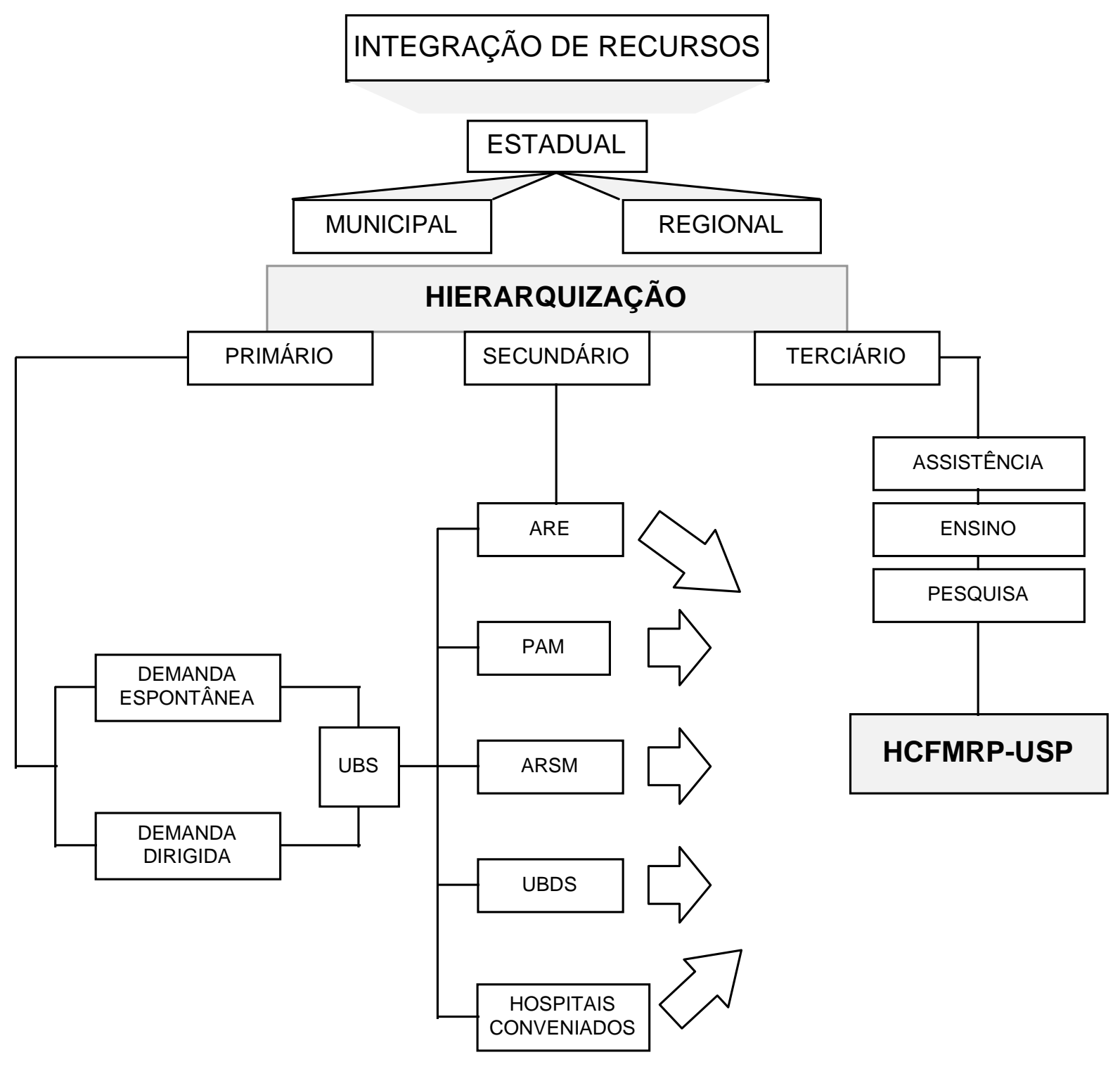

Figura 1 - Sistema Único de Saúde.

os diferentes níveis são previstos, e sua supervisão é da competência dos médicos das respectivas Unidades de Saúde que, formalmente, devem emitir uma "Ficha de Referência de Pacientes" (FRP) - em uso em todas as unidades, e o principal meio de conexão/comunicação entre os diferentes níveis. Após a conclusão desse atendimento solicitado, ou mesmo durante o processo de tratamento e investigação, o assistente solicitante receberá uma ficha semelhante a que emitiu, ou "Ficha de Contra-Referência". Ambas são relatórios sumários. A primeira, contendo as informações clínicas relevantes e os principais resultados dos exames preliminares, e a segunda, os resultados e diagnósticos definitivos ou planejamentos de tratamentos a serem seguidos. As solicitações de consultas e de atendimentos nos níveis secundário e terciário, sem a respectiva ficha, não são previstas - exceto quando se tratar de pacientes de outros estados ou urgências. Portanto, os encaminhamentos e solicitações de consultas e os atendimentos prestados mediante relatórios ou informações médicas, pessoais são considerados encaminhamentos/atendimentos não formais ou "extra-SUS". 


\section{Hospital das Clínicas - Objetivos e Organização}

O Hospital das Clínicas (HC) iniciou suas atividades em 1956, mediante convênio com a Fundação Maternidade Sinhá Junqueira, com as finalidades de: 1 - servir de campo de ensino e treinamento aos estudantes de Medicina e de Enfermagem, respectivamente, da Faculdade de Medicina e da Escola de Enfermagem de Ribeirão Preto da Universidade de São Paulo (respectivamente FMRPUSP e EERPUSP); 2 - prestar assistência médico - hospitalar à população não beneficiada pelos Institutos de Previdência Social ou por outros institutos - população "indigente", por definição; 3 - contribuir para a educação médica e sanitária do povo, em cooperação com as autoridades competentes; 4 - proporcionar meios para o desenvolvimento de pesquisas científicas.

No início da década de 60, o crescente fluxo migratório rural-urbano e o conseqüente aumento da pressão da demanda regional por serviços médicos, resultaram na necessidade de ampliação das instalações. Em 1962 iniciou-se então a construção do hospital próprio - anexo à Faculdade de Medicina, na Fazenda Monte Alegre. Com a mudança para as novas instalações, em 1977, as antigas, antes conveniadas, foram transformadas em Unidade de Emergência do Hospital das Clínicas - Pronto Socorro Regional e Unidade de Queimados (U.E.) - mantendo as características de hospital-escola, porém redefinindo estruturalmente suas finalidades: 1 - servir de campo de ensino e treinamento para estudantes dos cursos de graduação e pós-graduação das citadas faculdades e das escolas superiores relacionadas com a "Ciência da Saúde"; 2 - prestar assistência médica e hospitalar à população; $\mathbf{3}$ - servir de campo de aperfeiçoamento para profissionais relacionados com a assistência médica e hospitalar; $\mathbf{4}$ - proporcionar meios para o desenvolvimento de pesquisas científicas ${ }^{(18)}$. A partir da implantação do SUDS, em 1987, aquela categoria privilegiada, a quem o HC se destinava, deixou de existir por decisão política. Os atendimentos que até então se restringiam a uma parcela da população excluída dos benefícios dos institutos, foram estendidos a toda a população, sem restrições. Com a implementação da hierarquização, o HC passou a referenciar também a assistência médica e hospitalar, regional. Se, por um lado, esta hierarquização ampliou a oferta de serviços médicos altamente especializados, de leitos hospitalares em todas as especialidades e de serviços complementares de diagnósticos e tratamentos (compreendendo desde cuidados de prevenção, tratamentos e recuperação de natureza clínica e cirúrgica), com gratuidade total, por outro, determinou um aumento expressivo da demanda por esses serviços - simultaneamente à expansão da oferta de serviços dos níveis primário e secundário e ampliação das vias de acesso da população ao sistema.

Física e territorialmente, ocupa uma área de $83.000 \mathrm{~m}^{2}$ no Campus Universitário (USP), cujo complexo hospitalar funciona, atualmente, com 657 leitos - 452 no Campus e 205 na Unidade de Emergência. Atende, em média, 1400 pacientes por dia, em seus ambulatórios. Conta com 4082 funcionários entre as categorias técnicas e administrativas, bem como com 420 médicos - contratados, residentes, professores e docentes. Para isso, dispõe de aproximadamente 300 salas para atendimentos - entre elas 154 consultórios médicos, 18 salas de enfermagem, 3 consultórios odontológicos, 16 salas destinadas ao Serviço Social, além de salas de administração, medicamentos, repouso, coleta de material de exames, vacinas, quimioterapia, raio-X e outros ${ }^{(19)}$.

\section{MATERIAL E MÉTODOS}

O período de coleta dos dados foi de 14/6/93 a 13/7/93 - semanas consecutivas e sem interrupção nos atendimentos. A amostra foi definida por duplo sorteio - dos dias da semana e dos pacientes atendidos nos ambulatórios no período (participantes). Foram sorteados 2 dias para as entrevistas de cada semana e 2 outros da semana seguinte para as eventuais reposições das "perdas" da semana anterior. Os pacientes a serem entrevistados, foram sorteados, diariamente, entre os 40 primeiros das filas de espera das entradas principais do ambulatório e, a partir deles, todos os quadragésimos (das 7 às 18 horas). Foi assegurado o anonimato. No caso de recusa, foi convidado o imediatamente seguinte, dando continuidade ao processo, a partir dele. Os responsáveis diretos foram os respondentes das crianças menores e dos incapacitados. Os pacientes dos ambulatórios da Unidade de Emergência, Clínica Civil, e os que tiveram acesso ao hospital por outras vias não participaram desta pesquisa.

Os participantes foram entrevistados, após seu atendimento do dia, por uma das assistentes sociais do "staff" do Serviço Social Médico. Foi utilizado um questionário estruturado (Anexo I) e previamente testado. Cada entrevista teve duração média de 20 minutos. As informações utilizadas para este trabalho foram selecionadas desse questionário. O tamanho da 
amostra foi estimado em $1 \%$ do atendimento médio mensal. Foi tomada como referência a média de 1400 atendimentos/dia, com base nos relatórios disponíveis do ano anterior (1992), o que projetou 30800 consultas para os 22 dias úteis da pesquisa, ou 305-345 entrevistas (IC 95\%). Para as análises estatísticas (testes de proporções e associações) foi adotado o nível de significância $\mathrm{p} \leq 0.05^{(20)}$.

Quanto à procedência os participantes foram subdivididos em: 1 - de Ribeirão Preto (cidade e município); 2 - da região de abrangência do ERSA-50 (excluindo o primeiro); 3 - de todos os demais ERSA do Estado de São Paulo; 4 - de outros estados. Quanto aos locais dos encaminhamentos, foram divididos em 1 - portadores da Ficha de Referência de Pacientes (com FRP) - encaminhamentos formais, e $\mathbf{2}$ - não portadores (sem FRP). Os portadores da FRP foram classificados em: 1 - encaminhados pelo SUS (UBS, PA, CS, ARE, etc.), de qualquer procedência (inclusive de outros estados), 2 - pelo HC/UE - pacientes atendidos na Unidade de Emergência, de qualquer procedência, e encaminhados, posteriormente, para o ambulatório do HC (Campus), 3 - por HOSP - encaminhados para o ambulatório por qualquer hospital, conveniado ou não. Os não portadores da FRP foram classificados em: 4 - P/C - encaminhados por médicos particulares ou vinculados a convênios; 5 - M[C] por médicos da cidade de origem e não vinculados a convênios ou ao SUS; e 6 - procura espontânea - sem qualquer encaminhamento ou informação prévia.

As categorias ocupacionais foram codificadas por grupos, subgrupos e ocupações, a partir da classificação apresentada pelo $\operatorname{IBGE}^{(21)}$. O "perfil de morbidade" foi elaborado a partir do agrupamento dos diagnósticos, segundo a classificação do diagnóstico principal do atendimento (registrado no prontuário médico ou na respectiva ficha de atendimento) feito pelo Serviço de Documentação Médica do SAM (os pacientes internados e os encaminhados para internação previamente decidida não participaram desta pesquisa) Foram agrupados por grupos da CID - 1975 - lista tabular de inclusões e subcategorias ${ }^{(22)}$. Foi registrado um evento único do estado de saúde atual - o que obviamente não reflete a intensidade/gravidade, incidência ou prevalência das doenças nos diferentes locais de procedência $^{(23)}$. Por critério de juízo do autor, os diagnósticos classificados em 799.9 (Cap XVI - Causas mal definidas e/ou em investigação) e V01 a V82 (Classificação suplementar), foram considerados separadamente (Anexo II) e apresentados nas respectivas figuras.

\section{RESULTADOS}

\section{Demanda ambulatorial segundo a procedên- cia e local do encaminhamento}

Os procedentes de Ribeirão Preto representaram 40.7\% (124/305) dos atendimentos (consultas ou qualquer outro procedimento médico ambulatorial); destes, 56.4\% (70/124) portavam a respectiva Ficha de Referência de Pacientes (FRP), e haviam sido encaminhados pelo SUS, HC/UE e outros hospitais - portanto, encaminhamentos formais; 6.5\% (8/ 124) haviam sido encaminhados por médicos não ligados ao SUS (particulares, de convênios, outros não especificados), e $37.1 \%$ (46/124) eram de demanda espontânea Tabela I. Considerando - se o número médio estimado de atendimentos diários, essas proporções revelam que 248 dos 1400 pacientes/dia estariam sendo atendidos sem a respectiva FRP, presumivelmente excluídos do nível primário do sistema. Os pacientes procedentes da região do ERSA-50 representaram $27.2 \%$ (83/305) dos atendimentos diários. Destes, $50.6 \%(42 / 83)$ portavam a FRP; $31.3 \%$ (26/83) haviam sido encaminhados por médicos não ligados ao SUS, e 18.1\% (15/83) eram demanda espontânea. Os procedentes dos demais ERSA, representaram $21.6 \%$ (66/305) dos atendimentos. Destes, $33.3 \%$ (22/66) com FRP; $42.4 \%$ haviam sido encaminhados por médicos não ligados ao SUS; e $24.2 \%$ (16/66) eram demanda espontânea. Os procedentes dos demais estados representaram 10.5\% (32/305) dos atendimentos. Destes, $43.8 \%$ (14/32) foram atendidos na rede básica paulista e portavam a FRP; $40.6 \%$ (13/32) haviam sido encaminhados por outros médicos e $15.6 \%$ (5/32) eram demanda espontânea.

Os pacientes encaminhados via SUS, HC/EU e HOSP, independentemente da procedência, portanto com FRP, representaram 48.5\% (148/305) dos atendimentos. Os demais não portadores da FRP, representaram $51.5 \%$ (152/305). Nota-se que a procura espontânea representou $26.9 \%$ (82/305) do total dos atendimentos diários $-56.1 \%$ (46/82) procedentes de Ribeirão Preto.

\section{Demanda ambulatorial segundo as categorias ocupacionais dos pacientes}

A maior demanda dos atendimentos foi pelas categorias ocupacionais que, no mercado de trabalho, correspondem às de menores rendas - "Do lar", menores e dependentes, inativos e aposentados, outras 
Tabela I - Distribuição dos pacientes ambulatoriais segundo sua referência (FRP), procedência e local do encaminhamento

\begin{tabular}{|c|c|c|c|c|c|c|c|c|c|c|c|c|c|c|}
\hline \multirow{3}{*}{ Procedência } & \multicolumn{6}{|c|}{ Com FRP } & \multicolumn{6}{|c|}{ Sem FRP } & \multirow{2}{*}{\multicolumn{2}{|c|}{ TOTAL ** }} \\
\hline & \multicolumn{2}{|c|}{ SUS } & \multicolumn{2}{|c|}{ HC/UE } & \multicolumn{2}{|c|}{ HOSP } & \multicolumn{2}{|c|}{$\mathrm{P} / \mathrm{C}$} & \multicolumn{2}{|c|}{$\mathrm{M}(\mathrm{C})$} & \multicolumn{2}{|c|}{ P/E } & & \\
\hline & $\mathrm{n}$ & $\%$ & $\mathrm{n}$ & $\%$ & $\mathrm{n}$ & $\%$ & $\mathrm{n}$ & $\%$ & $\mathrm{n}$ & $\%$ & $\mathrm{n}$ & $\%$ & $\mathrm{n}$ & $\%$ \\
\hline RIBEIRÃo PrEto* & 33 & (27) & 32 & (26) & 5 & (4) & 4 & (3) & 4 & (3) & 46 & (37) & 124 & (40.7) \\
\hline ERSA-50 & 16 & (19) & 13 & (16) & 13 & (16) & 7 & (9) & 19 & (23) & 15 & (18) & 83 & $(27.2)$ \\
\hline OUtROS ERSA & 12 & (18) & 5 & (8) & 5 & (8) & 4 & (6) & 24 & (37) & 16 & (24) & 66 & (21.6) \\
\hline Estados & 8 & $(19)$ & 4 & (13) & 4 & $(13)$ & 5 & $(16)$ & 8 & $(25)$ & 5 & $(19)$ & 34 & (10.5) \\
\hline TOTAL & 69 & (22) & 54 & (18) & 27 & (9) & 20 & (7) & 55 & (18) & 82 & (27) & 307 & (100) \\
\hline
\end{tabular}

* Cidade e Município

** 1 paciente procedente da região do ERSA-50, não atendido no dia, não informou.

SUS - (compreende as UBS- Unidades Básicas de Saúde, UBDS- Unidades Básicas Distritais de Saúde, ARE- Ambulatórios Regionais de Especialidades, PS- Pronto Socorro, PAM- Pronto Atendimento Médico). HC/ UE (Unidade de Emergência do HC). HOSP (Todos os demais hospitais). P/C (Médicos de convênios ou particulares). $M(C)$ (Médicos da cidade de origem, não vinculados ao SUS). P/E (procura espontânea).

(ocupações mal definidas e não declaradas)/lavradores não proprietários, desempregados, e afastados temporariamente $-73.4 \%$ (226/308); e pelas demais categorias - prestação de serviços (autônomos), empregados das indústrias de transformação, do comércio, empregados em atividades administrativas, técnicas, no setor de transporte/comunicações, e agropecuária $-26.6 \%$ (82/308) Tabela II.

\section{Demanda ambulatorial segundo as categorias ocupacionais dos responsáveis pela família do paciente, e sua condição de atividade}

Dos responsáveis pelas famílias (inclusive o próprio paciente), $70.0 \%$ eram economicamente ativos $28.4 \%$, no setor primário da economia (Agropecuária, Extração Mineral e Pesca); 24.1\%, no secundário (Indústria de Transformação e Construção) e 47.5\%, no setor terciário (Comércio de Mercadorias e Serviços); $30.0 \%$ estavam inativos - dos quais $85.8 \%$, remanescentes das categorias de mais baixa renda ou inativos/aposentados (Tabela III).

\section{Distribuição dos atendimentos ambulatoriais segundo o tipo de atendimento}

As consultas "triagens médicas" corresponderam a $5.9 \%$ (18/308) dos atendimentos - 77.4\% (14/18) destes pacientes foram "dispensados" para seus locais de procedência e $22.6 \%$ (4/18) foram encami- nhados para consultas médicas nos ambulatórios de especialidades; $75.3 \%$ foram consultas ambulatoriais, previamente agendadas (rotinas) e $18.8 \%$ dos atendimentos foram devidos à solicitações externas (outros procedimentos e/ou exames subsidiários) (Tabela IV).

Tabela II - Distribuição dos pacientes segundo as categorias ocupacionais

\begin{tabular}{llrr}
\hline & Categorias Ocupacionais & $N$ & $\%$ \\
\hline 1 & Do Lar & 73 & 24 \\
2 & Menores (dependentes) & 59 & 19 \\
3 & InativosiAposentados & 57 & 19 \\
4 & Outrast'Lavradores & 26 & 9 \\
5 & Prestaçẫo de Serviç os & 23 & 8 \\
6 & Indústria de Transformaçẫo & 20 & 7 \\
7 & Comércio & 13 & 4 \\
8 & Administrativas & 10 & 3 \\
9 & Técnicas & 10 & 3 \\
10 & Desempregados & 9 & 3 \\
11 & TransportesiComunicaçổes & 4 & 2 \\
12 & Agropecuária & 2 & 1 \\
13 & Afastados temporariamente & 2 & 1 \\
\hline TOT ML & 308 & 100 \\
\hline
\end{tabular}

* Odupaçốes mal definadasinẫo dedaradas 
Tabela III - Distribuição dos responsáveis pela família do paciente (incluindo o próprio) segundo sua condição de atividade

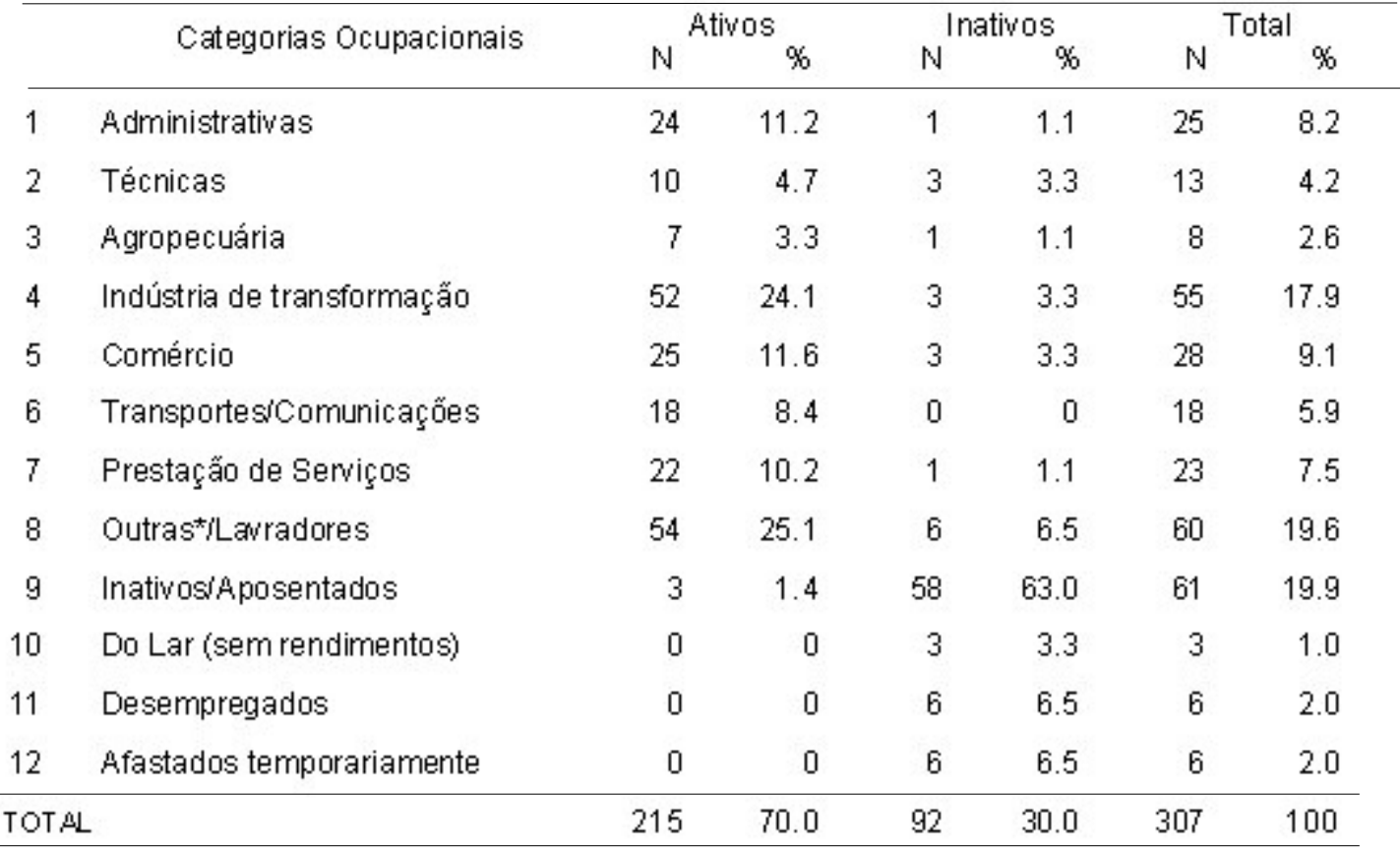

* Ocupaộ̃es mal definidasinẫo dedaradas.

Tabela IV - Distribuição dos pacientes segundo o tipo do atendimento e local

\begin{tabular}{lrrll}
\hline Tipo do atendimento & $\mathrm{N}$ & $\%$ & Tipo & $\%$ \\
\hline Triagem Médica & 18 & 5.9 & & \\
\hline - Dispensados & $(14)$ & 77.7 & & \\
- Encaminhados & $(4)$ & 22.3 & Triagem & \\
Consultas agendadas (rotinas) & & & & \\
- Clínica Médica & 59 & 19.2 & & \\
- Oftalmologia/Ortóptica & 36 & 11.7 & & \\
- Clínica Cirúrgica & 35 & 11.4 & & \\
- Ortopedia/Fisioterapia & 26 & 8.4 & & \\
- Ginecologia/Obstetrícia & 25 & 8.1 & & \\
- Neurologia/Psiquiatria & 25 & 8.1 & & \\
- Pediatria & 19 & 6.2 & & \\
- Otorrino / Fonoaudiologia & 7 & 2.3 & Consultas & \\
Procedimentos & & & & 100 \\
\hline - Radiologia / Radioterapia & 8 & 2.6 & & \\
- Exames e Agendamentos & 5 & 1.6 & & \\
- Outros Procedimentos & 45 & 14.6 & Procedimentos & \\
\hline Total & 308 & 100 & & \\
\hline
\end{tabular}




\section{Perfil da morbidade segundo o modo de acessso ao ambulatório (com e sem FRP)}

Entre os pacientes encaminhados (com FRP), as maiores demandas foram devidas às doenças contidas nos grupos de diagnósticos VI (16.1\%), II (12.1\%), X (8.5\%), VIII (4.9\%) e CID - 799.9 (13.5\%); e, entre os não encaminhados (sem FRP), foram devidas aos grupos VI(22.2\%), VIII (12.4\%), II (10\%), X (10\%)e CID - 799.9 $(3.7 \%)$, respectivamente. Entre essas categorias, as proporções de CID-799.9, e do grupo VIII, foram significativamente diferentes $(\mathrm{p}<0.05)$ (Figura 2). A primeira representa a proporção de pacientes cujos diagnósticos não puderam ser esclarecidos ou confirmados nos limites dos recursos - técnicos e pessoais - disponíveis ao nível da atenção primária e secundária, evidentemente necessitavam de assistência terciária. A segunda, demanda espontânea devida às doenças do aparelho respiratório, cuja assistência é, presumivelmente, de competência daqueles níveis de atenção, representa a proporção de pacientes que não foram assistidos - não tiveram acesso ao nível primário ou secundário, ou não tiveram esse problema de saúde equacionado ou resolvido satisfatoriamente. Com as exceções já mencionadas, todas as demais proporções entre os encaminhados e não encaminhados foram semelhantes.

\section{Perfil da morbidade por procedência}

As maiores demandas ambulatoriais foram devidas às doenças contidas nos grupos VI $(17.7 \%)$, II (11.5\%), CID-799.9(10.8\%) e X (8.9\%), cujas proporções foram semelhantes entre as diferentes procedências. A proporção de pacientes do grupo XIII, procedentes dos outros Estados, foi significativamente maior que a dos demais (Figura 3 ).

\section{Perfil de morbidade segundo as faixas etárias}

A demanda dos menores de 15 anos (Pediatria) representou $20.5 \%$ dos atendimentos ambulatoriais (Figura 4). As principais causas estavam contidas nos grupos de diagnósticos VI (28.6\%), VIII (15.9\%), CID 799.9 (12.7\%), XVI (9.5\%), e X (7.9\%); entre os pacientes de 15 a 35 anos (24.4\% dos atendimentos), as principais causas estavam contidas nos grupos VI (13.3\%), X (12.0\%), Especial (10.7\%), VIII (9.3\%) e III, IX, e XVII (8.0\% cada uma); entre os de 35 a 50 anos (24.4\% dos atendimentos), estavam contidas nos grupos II (16.0\%), VI e X (10.7\%), III, VII e Especial (8.0\%); entre os de 50 a 70 anos (20.9\% dos atendimentos), II e VI(17.2\%), Especial (14.1\%), III e XVII (7.8\%) e X (6.3\%); entre os maiores de 70 anos (9.8\% dos atendimentos), II (26.7\%), VI (23.3\%), XVII e Especial (10.0\%), e VII e XII (6.7\%). As proporções entre as faixas etárias foram significativamente diferentes para os grupos II, VIII e XVI .

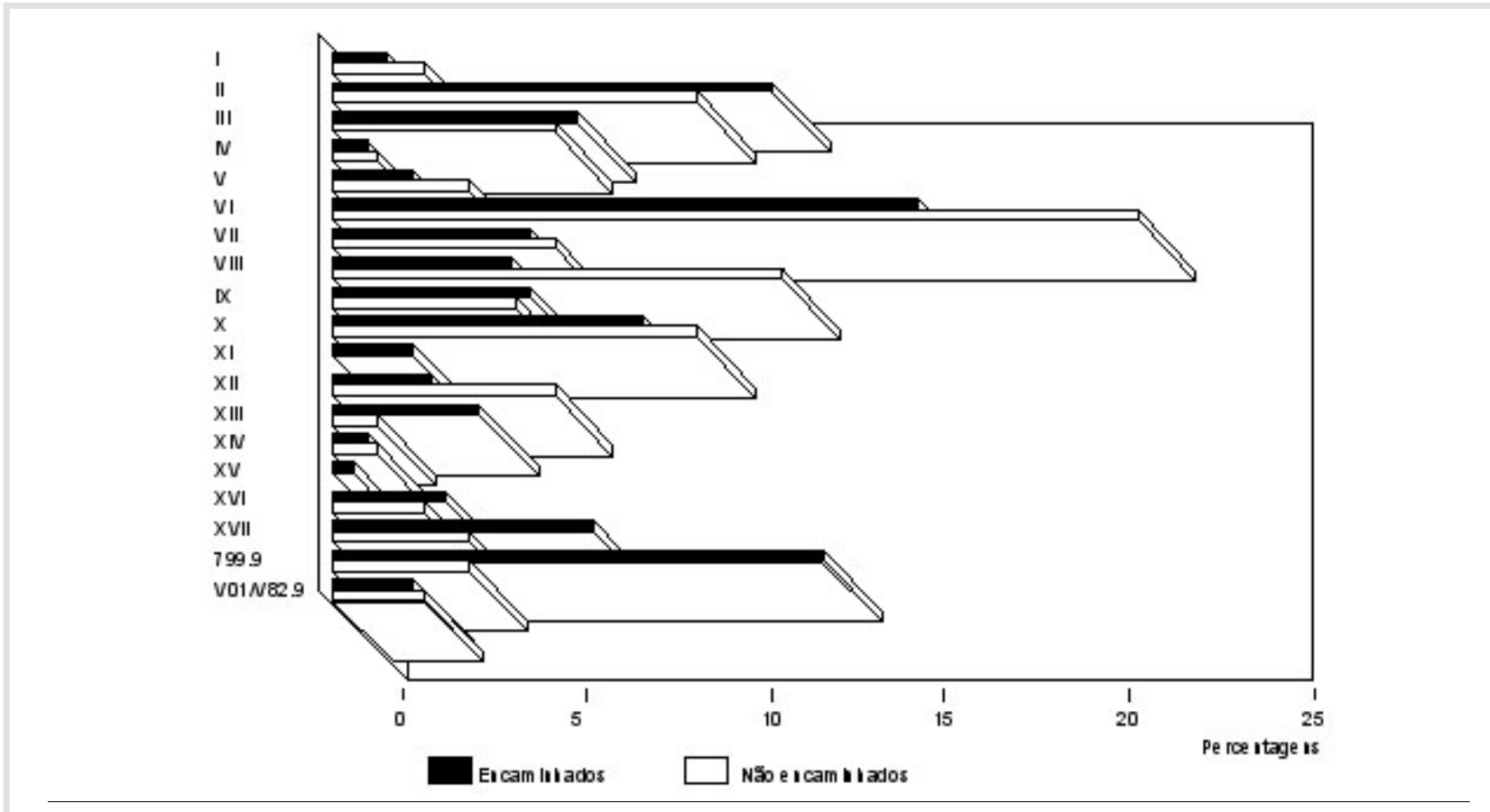

Figura 2 - Distribuição dos pacientes encaminhados e não encaminhados por grupos de diagnósticos. 

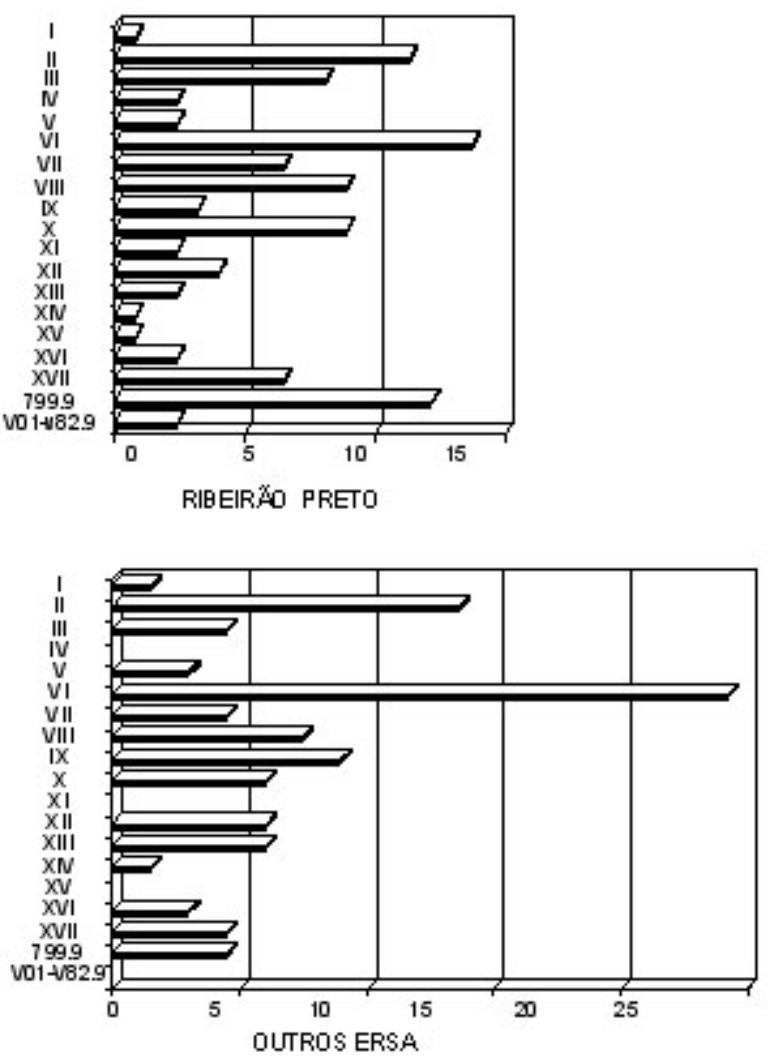
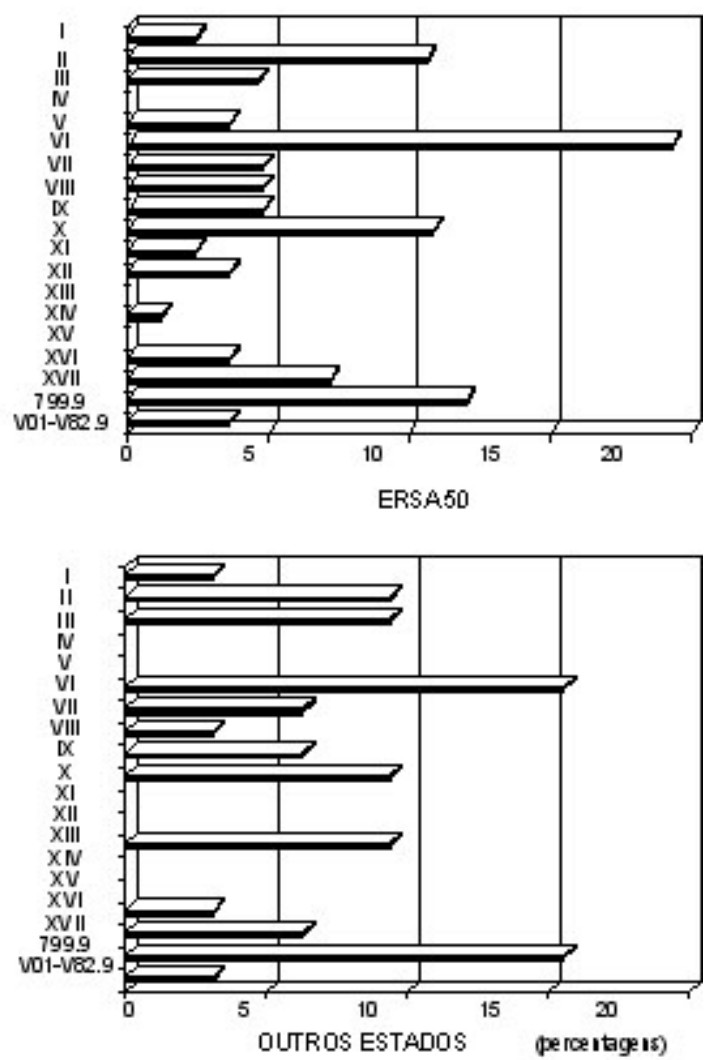

Figura 3 - Distribuição dos grupos de diagnósticos por regiões de procedências.

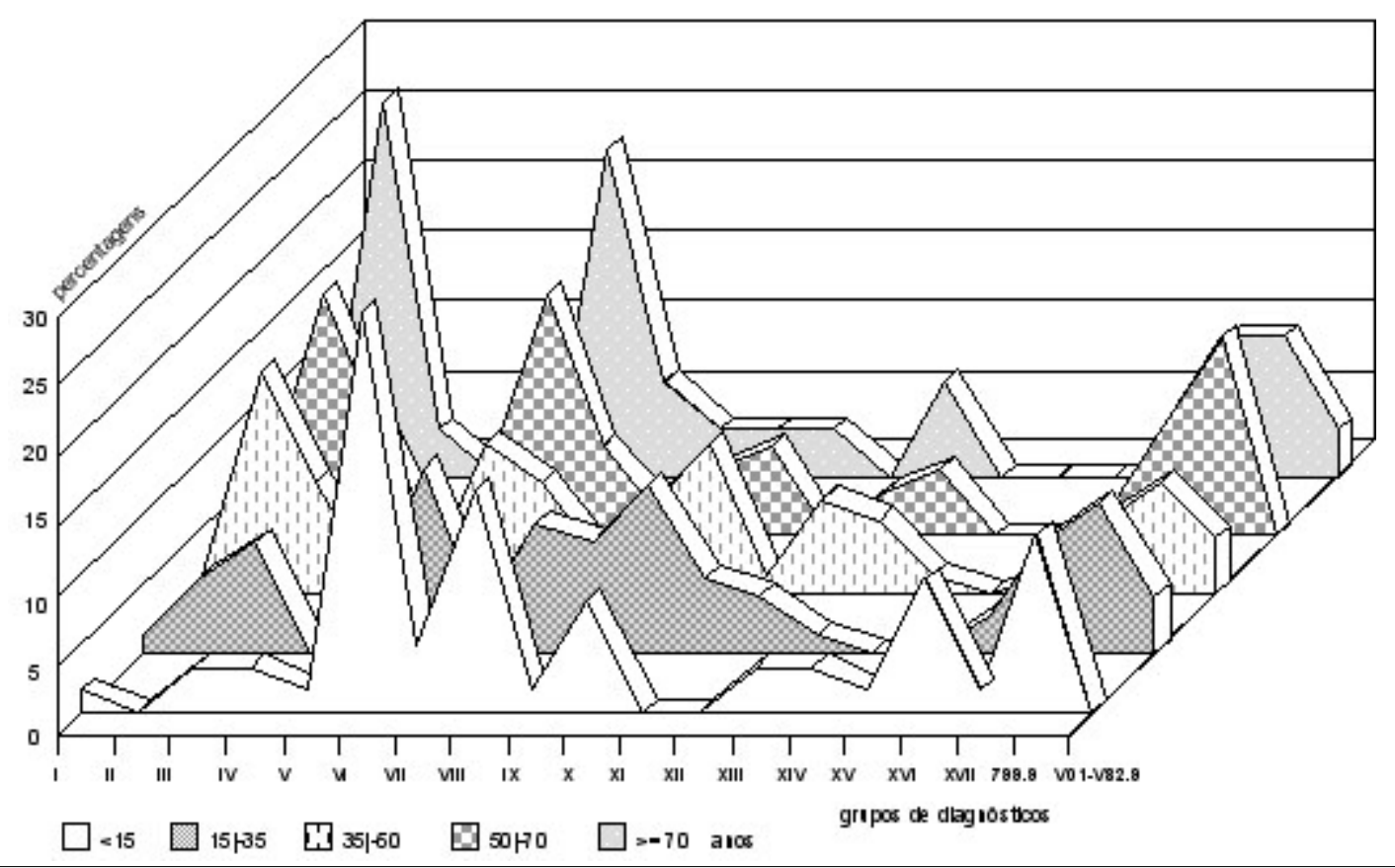

Figura 4 - Distribuição dos grupos de diagnósticos por faixas etárias. 


\section{Perfil de morbidade por sexo}

Entre os pacientes masculinos (42\% dos atendimentos) as maiores demandas foram devidas às doenças contidas nos grupos VI (19.4\%), II (11.6\%), CID - 799.91 (10.0\%), XVII (9.3\%), VIII e X (7.8\%) e entre o sexo feminino, VI (16.3\%), CID - 799.9 (11.8\%), II (11.2\%), X (9.6\%), VII (6.8\%), III e VIII (6.2\%) (Figura 5).

\section{DISCUSSÃO}

A constatação de que uma significativa parcela de pacientes foi atendida nos ambulatórios, sem a respectiva Ficha de Referência, pressupõe, sob o aspecto operacional, a não adesão da instituição aos pretendidos pressupostos da hierarquização e regionalização da assistência médica, uma vez que não atendeu, na prática, aos pressupostos normativos.

Por outro lado, os encaminhamentos indevidos para, e a procura espontânea por, um serviço médico à distância, com alta concentração de recursos humanos e tecnológicos, pressupõe: $\mathbf{1}$ - inacessibilidade geográfica, econômica, social e cultural ao nível primário, no local de origem; 2 - possível ineficácia dos procedimentos médicos nesses locais, ou uma inadequação técnica e profissional, resultando em ineficiência dos níveis primário e secundário; 3 - que atitudes negativas, nos demais níveis, não relacionadas com procedimentos médicos, necessariamente, condiciona a "fuga" do sistema; 4 - múltiplos atendimentos para um mesmo paciente, ou pelo mesmo "problema inicial" pelo qual fora encaminhado ("repiques"), ou utilizando-se da validade de seu registro para atendimentos não referenciados em outras clínicas; 5 - limites na comunicação entre os médicos (em todos os níveis) usando as Fichas de Referência e Contra-Referência. 6 - uma demanda espontânea "em si", decorrente de uma particular idealização de tecnologia como pressuposto de saúde, na medida em que a "oferta" (de serviços especializados com gratuidade total) cria, por si, uma particular necessidade de "consumo".

A demanda por categorias ocupacionais revela que ela foi predominantemente pelas categorias de baixa renda (sem rendas, dependentes, inativos/aposentados, lavradores, desempregados e afastados temporariamente) e $30.0 \%$ dos responsáveis (inclusive o paciente) estavam inseridos nos setores terciário da produção econômica e eram não economicamente ativos,

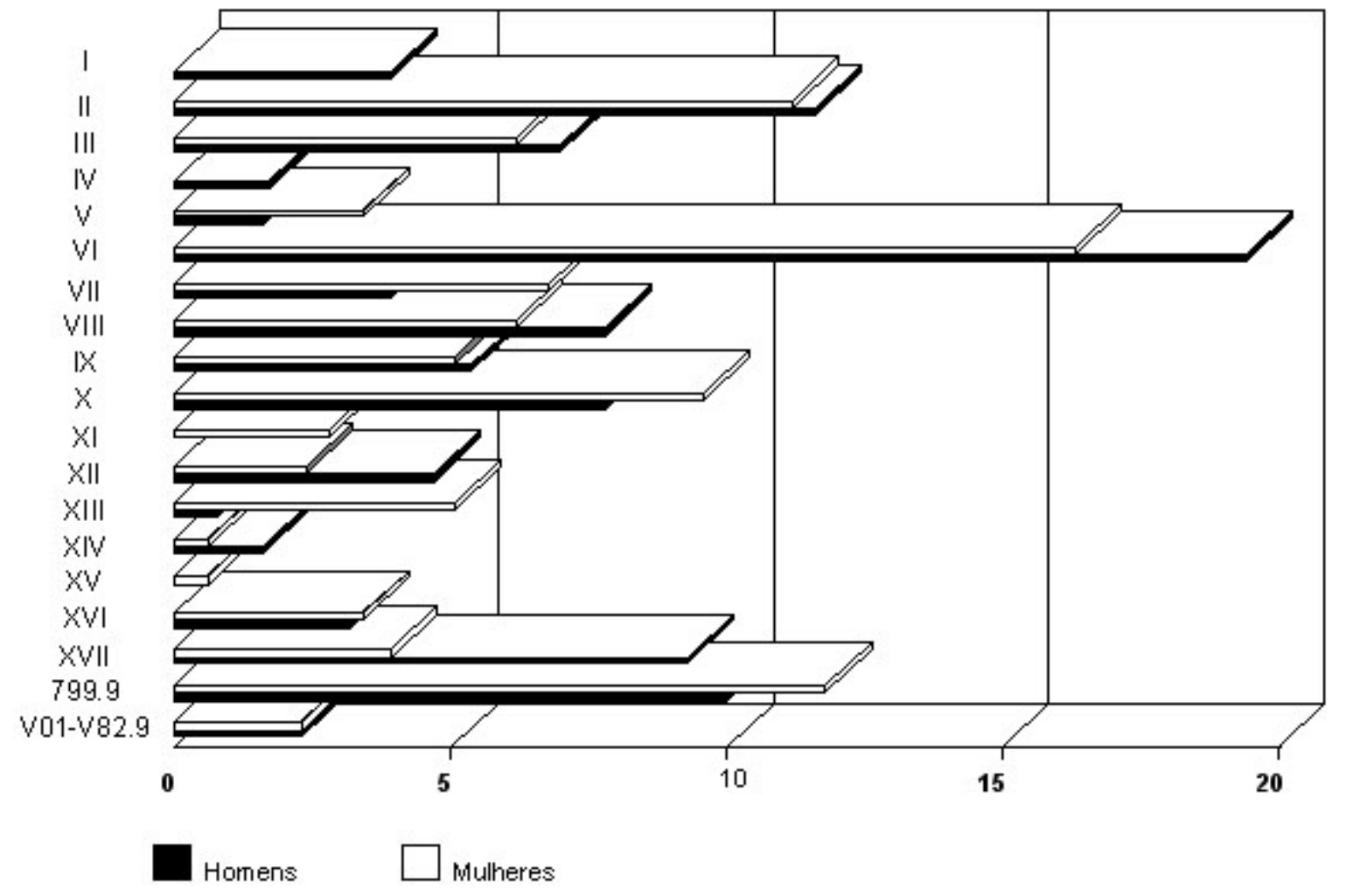

Figura 5 - Distribuição dos grupos de diagnósticos por sexo. 
portanto, excluídos do processo produtivo e do mercado de trabalho (Tabelas III e IV) e, indiscutivelmente, dependentes da assistência médica institucional. Compõem, em princípio, a mesma categoria a que o HC se destinava - a dos excluídos ou indigentes. Tal observação reproduz uma tendência observada mesmo nos países industrializados ${ }^{(24,25)}$.

Os pacientes dispensados após o primeiro atendimento (triagem) poderiam ter sido atendidos nos respectivos locais de origem (Tabela V). Esse contingente representou cerca de 1400 consultas/mês. Os encaminhados para "atendimento no dia" (os pacientes que, por critério médico, realmente necessitavam dos recursos do nível terciário, juntamente com as consultas de "seguimento ou retorno médico" e "casos novos" agendados $(75.3 \%$ das atividades ambulatoriais) representaram o total dos atendimentos ambulatoriais, correspondentes ao nível terciário, para os quais o HC está dimensionado.

Não foi possível diferenciar os procedimentos (exames clínicos e laboratoriais, radiodiagnóstico, radioterapia, substituição de aparelhos gessados, fisioterápicos, etc.) que foram solicitados via SUS ou por outras vias. Representaram $18.8 \%$ das atividades de rotina (estimativamente 5.790 pacientes por mês).

A comparação do perfil de morbidade dos pacientes "encaminhados" com "não encaminhados" permite concluir que estes tinham necessidades específicas e bem definidas - as proporções deles nos diferentes grupos de doenças foram, na sua maioria, estatísticamente semelhantes - principalmente em relação aos grupos I. Doenças Infecciosas e Parasitárias, II. Neoplasmas, III. Doenças das Glândulas Endócrinas..., IV. Doenças do Sangue..., V. Transtornos Mentais, VII. Doenças do Aparelho Circulatório, IX. Doenças do Aparelho Digestivo, X. Doenças do Aparelho Geniturinário, XIV. Anomalias Congênitas, XVI. Sintomas e Afecções Mal Definidas, e V01/V82 - Fatores que influenciam o estado de saúde (Figura 2). Isto pressupõe que havia algum conhecimento prévio do estado de saúde (diagnósticos anteriores, para confirmações, falência de tratamento ou agravamentos, identificação, pelos pacientes, das limitações dos recursos locais, disponíveis, etc.).

Os grupos de diagnósticos VIII e XII, com demanda significativamente maior entre os não encaminhados, por requererem recursos de pequena e média complexidade, podem estar refletindo limitações de recursos nos locais de origem - médicos ou tecnológicos. De outra forma, surgiriam nas mesmas propor- ções que os "encaminhados". A maior proporção dos pacientes da classificação 799.9 (doenças sem diagnóstico ou em investigação) entre os encaminhados indica uma necessidade real da assistência terciária, independentemente da procedência e local do encaminhamento. Da mesma forma que os grupos de diagnósticos II, VI, e XIII, permitem inferir uma associação entre os diagnósticos que eles contêm e os recursos disponíveis, as maiores frequiências dos grupos II, III, VI, X, XVII e CID 799.9, observadas por procedências, também confirmam essas necessidades locais e específicas, ou suas limitações (Figura 3). Trata-se de grupos de diagnósticos que exigem recursos com alto grau de especialização, diagnósticos de moderada complexidade e terapêutica de longa duração, para os quais o SUS, no nível da atenção secundária, não está dimensionado, e os convênios não oferecem cobertura (setor privado).

Quanto às faixas etárias, entre os maiores que 35 anos, prevaleceu o grupo II. Neoplasmas - para o qual o SUS dispõe de hospitais regionais especializados - cujo tratamento, como comentado, exige procedimentos diagnósticos e terapêuticos de alto custo e/ou de longa duração, que não estão cobertos pela maioria dos convênios. Entre os menores de 15 anos (Pediatria), prevaleceu o grupo VIII. Doenças do Aparelho Respiratório, com a mesma proporção entre os encaminhados e não encaminhados. Engloba procedimentos diagnósticos e terapêuticos dos níveis primário e secundário, para os quais as UBS, as UBDS, o ARE e os hospitais de nível secundário estão equipados para atendimentos eficazes e com alta resolubilidade (Figura 4).

Quanto ao sexo, houve maior tendência de utilização dos serviços ambulatoriais pelas mulheres. Resultado também observado por D'OLEO \& FAVERO, em 1988, nos hospitais da região ${ }^{(26)}$, principalmente na faixa etária de 15-35 anos ( $\mathrm{p}=0.003)$ e nos grupos XI, Complicações do parto e puerpério, e XIII, Osteomuscular e tecido conjuntivo.

Os resultados permitem levantar algumas questões polêmicas das políticas de saúde (quanto à universalização pretendida, da participação do setor privado, e da alocação de recursos médicos e tecnológicos), bem como da eficácia da assistência médica. Também demonstram que há um significativo contingente de pacientes "não encaminhados", não portadores de guias de encaminhamento (independentemente dos diagnósticos), principalmente procedentes de $\mathrm{Ri}$ beirão Preto e assistidos por médicos sem vínculos com 
o SUS, procedentes da região do ERSA-50, e dos demais ERSA, que poderiam ter tido o seu problema de saúde assistido no local de origem - o que faz pressupor que, ou não tiveram acesso, ou foram excluídos da assistência nos demais níveis (cujas causas intrínsecas não foram objetos desta pesquisa). Revela-se, por esse lado, a ineficiência desses níveis na cidade e nos municípios da região.

A emissão das Fichas de Referência e Contra-Referência deveria ser estimulada e adotada como um procedimento obrigatório (nos dois sentidos, como proposta inicialmente) a despeito das suas limitações ${ }^{(27)}$. Embora não seja uma solução para um problema cuja natureza transcende às questões burocrá- ticas, é, sem dúvida, um meio racionalizador do trabalho médico na medida em que direciona o fluxo dos pacientes que realmente necessitam de outros recursos além dos disponíveis, nos níveis primário e secundário. Essa comunicação é fundamental para a otimização dos atendimentos.

\section{AGRADECIMENTOS}

Agradecemos à Superintendência do Hospital das Clínicas, FAEPA, assistentes sociais do Serviço Social Médico, respectivas funcionárias e agentes hospitalares, que deram suporte técnico e participaram da fase de campo desta pesquisa.

GUTIERREZ MR \& BARBIERI MA. Unified health system and outpatient clinic demand - the patients of the University Hospital of the Faculty of Medicine of Ribeirão Preto - USP. Medicina, Ribeirão Preto, 31: 81-98, jan./march 1998.

ABSTRACT: Objective - To study the socioeconomic aspects and the morbidity of patients seen at the outpatient clinics of UHFMRP-USP. Material and Methods - A total of 308 patients were interviewed after being selected by a probabilistic sampling process. Morbidity was described on the basis of the respective groups of major diagnoses (IDC-1975). Results-Most patients belonged to low income occupational categories; $70 \%$ were economically active; $40.7 \%$ were from Ribeirão Preto (37.1\% appered without referral); $27.2 \%$ from ERSA 50 region (18.1\% without referral); $21.6 \%$ from the remaining ERSA (24.2\% without referral); $10.5 \%$ from other states $(15.6 \%$ without referral). Medical screening corresponded to $6 \%$ of the daily visits $(77.7 \%$ these were dismissed); the visits schedule at the specialized outpatient clinics represented $75.3 \%$ of the total, and $18.8 \%$ of the visits were due to other procedures. With respect to morbidity, here was a higher search for Pneumology assistence (Diseases of the Respiratory Tract) among the patients without referral, and undiagnosed diseases or diseases to be investigated among referred patients; the highest demand was due to Diseases of the Nervous System, Neoplasm,Supplementary Diagnoses (V01 to V08) and Diseases of the Genitourinary Tract. Conclusions - In practice, visits at the outpatients clinic with a referral form do not satisfy the assumptions of hirarchization; a considerable number of patients could have been seen in the respective basic units, suggesting na exclusion of the primary and secundary levels, whose causes were not determined; the greatest demand was on part of Ribeirão Preto residents and the procedures most often requested were those of high cost and/or involving prolonged treatments.

UNITERMS: Health System. Outpatient Clinics Hospital. Morbidity. Hospitals, University.

\section{REFERÊNCIAS BIBLIOGRÁFICAS}

1 - BRASIL. MINISTÉRIO DAPREVIDÊNCIAEASSISTÊNCIASOCIAL. Decreto $94657 / 87$ de 20 de Julho de 1987. Diário Oficial da União, Brasília, 21 Julho 1987.

2 - LOBO LC. Sistemas de saúde. Análise e proposta. Educ Med Salud 20: 222-234, 1986.

3 - BERLINGUER G. Medicina e política. HUCITEC, São Paulo, 1987.
4 - TANAKA OY. Demanda do sistema de saúde. Saúde em Debate 28: 38-40, 1989.

5 - QUEIROZ MS \& VIANA AL. Padrão de política estatal em saúde e o sistema de assistência médica no Brasil atual. Rev Saúde Pública 26: 132-140, 1992.

6 - GONÇALVES RB. Tecnologia e organização social das práticas de saúde: características tecnológicas do processo de trabalho na rede estadual de Centros de Saúde de São Paulo. Tese de Doutorado, Faculdade de Medicina da USP, São Paulo, 1986. 
7 - SCHRAIBER LB. The challenge of medical education faced with new economic and technological paradigms. Educ Med Salud 28: 20-52, 1994.

8 - BANTA HD. Medical technology and developing countries: the case of Brasil. Int J Health Serv 16: 363-373, 1986.

9 - LAURELL AC. La salud-enfermedad como processo social. Rev Latinoam Salud 1: 2-25, 1982.

10 - ILLICH I. A expropriação da saúde. Nova Fronteira, Rio de Janeiro, 1975.

11 - ROSENSTOCK IM. Por que la gente utiliza los servicios de salud. In: ORGANIZAÇÃO MUNDIAL DA SAÚDE. Investigaciones sobre servicios de salud: una antologia. Publ Cient 534: 405-423, 1991.

12 - COHN A et al. A saúde como direito e como serviço. Cortez, São Paulo, 1991.

13 - FRENK J. Concept and measurement of accessibility. Salud Publica Mex 27: 438-453, 1985.

14 - RODRIGUES FILHO. Utilização hospitalar no Brasil e o efeito das medidas de contenção do crescimento de hospitalizações. Rev Ass Med Brasil 35: 197-201, 1989.

15 - SÃO PAULO (Estado). Decreto 40083/95 de 15 de Maio de 1995. Diário Oficial do Estado, São Paulo, 16 Maio 1995.

16 - OTHAKE F \& SALES T. Caracterização sócio econômica da região de Ribeirão Preto. Centro Brasileiro de Análises e Planejamento, São Paulo, Jan. 1983.

17 - MERCADANTE OA et al. Descentralizacion y municipalizacion de los servicios de salud en São Paulo, Brasil. Bol Of Sanit Panam 116: 381-396, 1994.

18 - SUPERINTENDÊNCIA DO HOSPITAL DAS CLÍNICAS DA FACULDADE DE MEDICINA DE RIBEIRÃO PRETO DA UNIVERSIDADE DE SÃO PAULO. História do Hospital das Clínicas/mimeografado.
19 - SUPERINTENDÊNCIA DO HOSPITAL DAS CLÍNICAS FACULDADE DE MEDICINA DE RIBEIRÃO PRETO DA UNIVERSIDADE DE SÃO PAULO. Relatório de atividades, 1992.

20 - SPIEGEL MR. Estatística. 3 ed. Makron Books, São Paulo, 1993.

21 - BRASIL. SECRETARIA DO PLANEJAMENTO DA PRESIDÊNCIA DA REPÚBLICA. IX Recenseamento Geral do Brasil 1(49) (tomo 4 , anexo III): 54-60, 1980.

22 - ORGANIZAÇÃO MUNDIAL DE SAÚDE. Classificação Internacional das Doenças. Revisão 1975. OMS, Genebra, 1975.

23 - LAURENTI R et al. Estatísticas de saúde. 2 ed. EPU, São Paulo, 1987.

24 - BORRAS JM. Utilizacion de los sevicios de salud. Gac Sanit 8: 30-49, 1994.

25 - MUSTARD CA \& FROLICH N. Socioeconomic status and the health of the population. Med Care 33: DS43-DS54, 1995. Suppl 12.

26 - D'OLEO R \& FAVERO M. Perfil sociodemográfico da população que damanda assistência médico-hospitalr em região do Estado de São Paulo, Brasil, 1988. Rev Saúde Pública 26: 256-263, 1992.

27 - ISAAC DR et al. The GP-hospitalar interface: attitudes of general practitioners to terciary teaching hospitals. Med $\mathbf{J}$ Aust 166: 9-12, 1997.

Recebido para publicação em 06/09/1996

Aprovado para publicação em 10/12/1997 


\section{Anexo I}

\section{"PROJETO: PACIENTES AMBULATORIAIS" Hospital das Clínicas da Faculdade de Medicina de Ribeirão Preto}

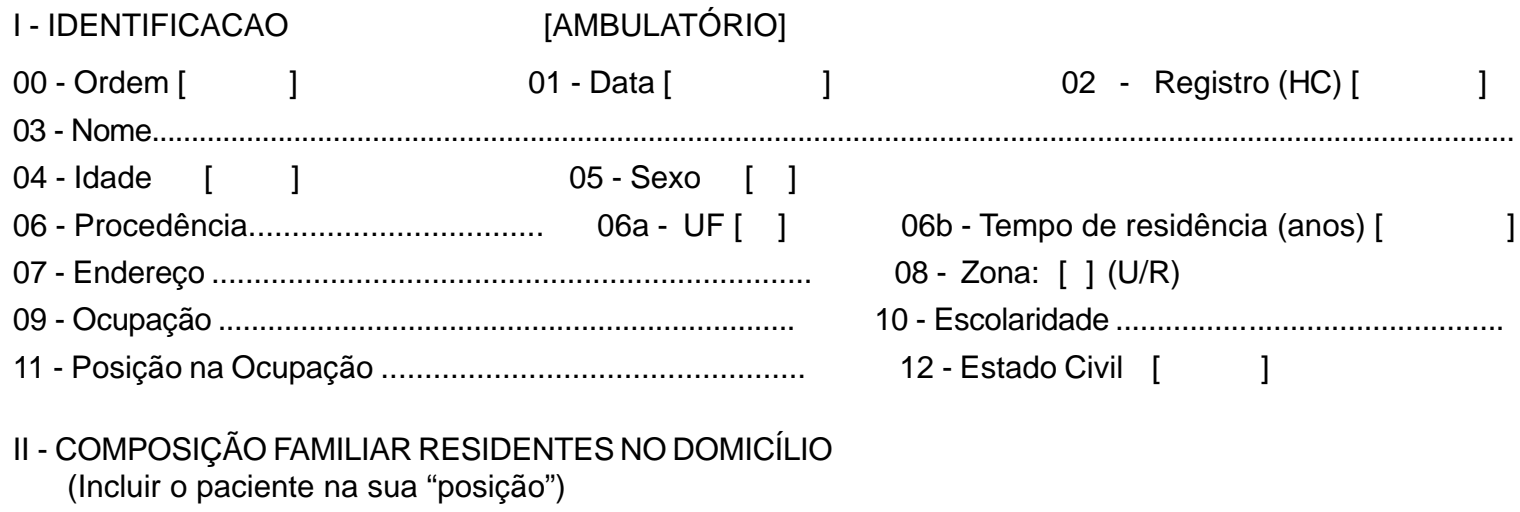

\begin{tabular}{|c|c|c|c|c|c|}
\hline Grau de Parentesco & Idade (anos) & Escolar (Abrev.) & Estado Civil & Ocupação & Atividade $(\mathrm{A} / \mathrm{I})$ \\
\hline 13 - Pai (R-1) & $|13| \mid$ & $|13 \mathrm{E}|$ & $|13 C|$ & $|130|$ & $|13 \mathrm{~A}|$ \\
\hline 14 - Mãe (R-2) & $|14| \mid$ & $|14 \mathrm{E}|$ & $|14 C|$ & |140 & $|14 \mathrm{~A}|$ \\
\hline 15 - Filho 1 & $|15| \mid$ & $|15 \mathrm{E}|$ & $|15 \mathrm{C}|$ & $|150|$ & $|15 A|$ \\
\hline 16 - Filho 2 & $|16| \mid$ & $|16 \mathrm{E}|$ & $|16 C|$ & |160| & $|16 \mathrm{~A}|$ \\
\hline 17 - Filho 3 & $|17| \mid$ & $|17 \mathrm{E}|$ & $|17 C|$ & |170 | & $|17 \mathrm{~A}|$ \\
\hline 18 - Filho 4 & $|18| \mid$ & $|18 \mathrm{E}|$ & $|18 C|$ & |180 | & $|18 \mathrm{~A}|$ \\
\hline 19 - Agregado1 & $|19| \mid$ & $|19 E|$ & $|19 C|$ & |190| & $|19 A|$ \\
\hline 20 - Agregado2 & $|201|$ & $|20 \mathrm{E}|$ & $|20 C|$ & |200| & $|20 \mathrm{~A}|$ \\
\hline 21 - Outros & $|21| \mid$ & $|21 \mathrm{E}|$ & $|21 \mathrm{C}|$ & |210| & $|21 \mathrm{~A}|$ \\
\hline
\end{tabular}

22 - Tipo de Família:

III - RENDAFAMILIAR

RENDA FAMILIAR BRUTA [Soma da renda de todos participantes]

23 - Renda mínima 24 - Renda máxima

Número de pessoas na família [ ] Salário Mínimo de Referência RENDAPER CAPITA: 25 - Mínima . 26 - Máxima

FRAÇÃO DA REF. (PC)* 27 - Mínima 28 - Máxima

IV - HABITAÇÃO Ocupada Coletiva $\square \quad$ Financiada

30 - Tipo de Construção:

Alvenaria

Madeira

31 - Outros cômodos são utilizados como quartos?
Barraco

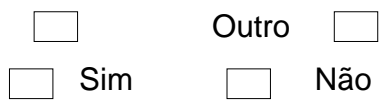

* Fração da renda familiar em porcentagem do salário mínimo 


\section{V - SANEAMENTO E ESGOTAMENTO}

32 - Dispõem de água encanada dentro de casa?

33 - Dispõem de água tratada?

$\square \operatorname{Sim}$

$\square$ Não

34 - Qual a fonte (origem) do abastecimento?

35 - Dispõem de "privada" ? Dentro

Fora

Sim $\square$ Não

$\square \quad$ Ignorado

36 - Vocês dispõem de luz elétrica?

Não Dispõem

37 - Quais os meios de transporte que o Senhor(a) usa com mais freqüência?

38 - No bairro onde vocês moram tem:

\begin{tabular}{|c|c|c|c|}
\hline 38a - Asfalto & $\square$ & Sim & $\square$ \\
\hline 38b - Iluminação Pública & $\square$ & Sim & $\square$ \\
\hline 38c - Ônibus Urbano & $\square$ & Sim & $\square$ \\
\hline 38d - Telefone Público & $\square$ & Sim & $\square$ \\
\hline 38e - Escola Primária & $\square$ & Sim & $\square$ \\
\hline $38 \mathrm{f}-\mathrm{CS} / \mathrm{UBs} / \mathrm{PAM} / \mathrm{PS}$ & $\square$ & Sim & $\square$ \\
\hline 38g - Bares/Botequins & $\square$ & Sim & $\square$ \\
\hline 38h - Pequeno Comércio & $\square$ & Sim & $\square$ \\
\hline 38i - Lugares para Esporte/ Laser & $\square$ & Sim & $\square$ \\
\hline 38j - Parques ou Creches & $\square$ & Sim & $\square$ \\
\hline
\end{tabular}

VI - REGIME DE TRABALHO DO RESPONSÁVEL PELAFAMÍLIA

39 - Tipo de trabalho/atividade .

40 - Quantas horas trabalha por dia?

41 - Quanto tempo de intervalo durante o trabalho?

42 - Quanto tempo "gasta" para chegar ao local de trabalho?

43 - Que meio de transporte usa para ir ao trabalho?

44 - Usa algum equipamento de segurança para o tipo de trabalho que executa?

\section{VII - ACESSIBILIDADE AO HOSPITAL E ASSISTÊNCIA MÉDICA}

45 - Que horas o Senhor(a) saiu de casa?

46 - Que horas o Senhor(a) chegou ao hospital?

47 - Que transporte o Senhor(a) utilizou?

48 - Que horas o Senhor(a) foi atendido pelo médico?

49 - O Senhor(a) foi encaminhado(a)? ................................................ $\square \quad \operatorname{Sim} \quad \square \quad$ Não

50 - Quem encaminhou?

50a - Qual seu atendimento hoje?

\section{VIII - PERCEPÇÃO DA SAÚDE/DOENÇA}

51 - Como o Senhor(a) percebeu que precisava ir ao médico?

52 - Por que procurou este hospital?

53 - O Senhor(a) já fez/fazia algum tratamento antes? Há quanto tempo?

54 - O Senhor(a) deixou de trabalhar ou mudou de atividade por causa da sua doença ATUAL? 
55 - Quantos dias de trabalho útil o Senhor(a) já perdeu por causa do seu problema atual de saúde?

56 - Quantas vezes o Senhor(a) precisou vir a este hospital por causa do seu problema?

$56 a$ - Conseguiu ser atendido?.

57 - Do que o Senhor(a) "não gostou" no atendimento geral do hospital?

58 - Correspondeu ao que o Senhor(a) esperava?

59 - $\square \operatorname{Sim} \square$ Não Por que?

60 - O médico(a) que o(a) atendeu falou sobre seu problema?

$60 a$ - Qual é seu problema?

60b - [CID - ] ] (ATUAL - do prontuário do atendimento)

61 - O Senhor(a) não entendeu alguma coisa do que the foi explicado?

Por quê?

62 - O Senhor(a) acha possível seguir o tratamento / orientações que foram recomendados ?

Por quê?.

\section{IX - ATENDIMENTOS DOS PROFISSIONAIS NÃO MÉDICOS}

63 - O que o Senhor(a) achou de todos os atendimentos / procedimentos que the prestaram?

\section{$X$ - TIPO DE ATENDIMENTO/ENCAMINHAMENTO}

\begin{tabular}{|c|c|c|}
\hline \multicolumn{2}{|l|}{ Atendimento } & Destino \\
\hline Triagem médica & (1) & ( a ) Dispensado para UB \\
\hline Pronto Atendimento & ( 2 ) & ( b ) Dispensado para CS / ARE \\
\hline "Caso Novo" & ( 3 ) & ( c ) Dispensado para outros Hospitais \\
\hline Retorno "Pronto Atendimento" & ( 4 ) & (d ) Dispensado para Unidade de Emergência \\
\hline \multicolumn{3}{|l|}{ Retorno/ "Retorno Ambulatório } \\
\hline Especializado" & ( 5 ) & ( e ) Dispensado para outro dia \\
\hline "Fora de Dia" & (6) & (f) Remarcar Retorno \\
\hline Efetuar Exames & ( 7 ) & (g ) Encaminhado para atendimento no dia \\
\hline \multirow[t]{3}{*}{ Internação Rotina } & ( 8 ) & ( h ) Marcar Retorno $(\mathrm{CN})$ \\
\hline & & (i ) Colher Exames \\
\hline & & ( j ) Pedido de consulta/outra clínica \\
\hline \multirow[t]{4}{*}{ Outros } & (9) & ( $\mathrm{k}$ ) Encaminhado para Triagem \\
\hline & & ( I ) Internação no Dia \\
\hline & & ( $\mathrm{m}$ ) Aguardar \\
\hline & & ( $\mathrm{n}$ ) Alta \\
\hline
\end{tabular}

64 - CÓDIGO - [ ] [ ] [ ] [ ]

65 - O Senhor(a) gostaria de falar algo que não the foi perguntado?

Data da entrevista:

Nome do(a) Entrevistador(a): 


\section{Anexo II}

\section{Grupos de diagnósticos, CID 799.9 e classificação suplementar (V01 a V82)}

I. Doenças Infecciosas e Parasitárias

II. Neoplasmas

III. Doenças das Glândulas Endócrinas, Nutrição e Metabolismo. Transtornos Imunitários

IV. Doenças do Sangue e Órgãos Hematopoiéticos

V. Transtornos Mentais

VI. Doenças do Sistema Nervoso e dos Órgãos dos Sentidos

VII. Doenças do Aparelho Circulatório

VIII. Doenças do Aparelho Respiratório

IX. Doenças do Aparelho Digestivo

X. Doenças do Aparelho Geniturinário

XI. Complicações da Gravidez, do Parto, e do Puerpério

XII. Doenças da Pele e do Tecido Celular Subcutâneo

XIII. Doenças do Sistema Osteomuscular e do Tecido Conjuntivo

XIV. Anomalias Congênitas

XV. Algumas Afecções Originadas no Período Perinatal

XVI. Sintomas, Sinais e Afecções Mal Definidas

XVII. Lesões e Envenenamentos

CID 799.9 Sem Diagnóstico ou em Investigação

CID V01 - V82 Fatores que influenciam o estado de saúde 